2017-08-25

\title{
An evaluation of a two-site pilot model for dental foundation training
}

\author{
Urzinger, Sebastian
}

http://hdl.handle.net/10026.1/11390

10.1038/sj.bdj.2017.714

British Dental Journal

Nature Publishing Group

All content in PEARL is protected by copyright law. Author manuscripts are made available in accordance with publisher policies. Please cite only the published version using the details provided on the item record or document. In the absence of an open licence (e.g. Creative Commons), permissions for further reuse of content should be sought from the publisher or author. 
Title:

AN EVALUATION OF A TWO-SITE PILOT MODEL FOR DENTAL FOUNDATION TRAINING

ALI K, KHAN S, BRIGGS P, JONES E

British Dental Journal 223(4):287-292 25 Aug 2017

Reporting date: 25 Aug 2017

Date of Acceptance: 17/07/2017 


\section{ABSTRACT}

Objectives: To evaluate the feasibility, strengths, weaknesses, and challenges of a two-site model of Dental Foundation Training.

Methods: A mixed methods approach was used to evaluate the two-site pilot. Qualitative interviews and focus groups were employed to gain an in-depth understanding of the expectations, experiences and concerns of the stakeholders. Additionally, purposefully designed questionnaires were used to rate different elements of the training.

Results: Participants included 12 Foundation Dentists, 15 Educational Supervisors and 7 Assistant Educational Supervisors. An increased breadth of clinical experience, a more variable case-mix, feedback from two teams of supervisors, and the experience of working within two different practices with two different teams and cultures were perceived to be the main strengths. The key challenges reported by the trainers were increased workload, a perceived disruption to the continuity of patientcare and perceived difficulties in establishing professional relationships.

Conclusions: This paper reports on the evaluation of a new model of Dental Foundation Training in London. It highlights potential advantages and drawbacks of providing dental foundation training in two dental practices. Given the limitations of the of evaluation reported in this paper, additional work is required to establish the feasibility and effectiveness of the two-site training model.

Key Words: Dental; Education; Foundation Training; Pilot 


\section{INTRODUCTION}

Dental Foundation Training (DFT), formerly known as Vocational Training (VT) is a mandatory requirement for all dentists who wish to practice within NHS primary care settings in England. ${ }^{1}$ At the end of training the trainees are issued with a Certificate of Satisfactory Completion by their Postgraduate Dental Dean allowing them to apply for an NHS performer list number.

DFT involves a newly qualified dentist, currently referred to as Foundation Dentist (FD) working under the supervision of an approved Educational Supervisor (ES) for one year with a contract to provide NHS General Dental Services (GDS). There are approximately 72 programmes (schemes) running in England across ten Health Education England (HEE) regions. Some programmes offer DFT in Community Dental Services (CDS) and a small number offer DFT in prototype contract practices. In contrast, the Foundation Training programme for medical doctors involves two years of mandatory training under multiple supervisors in a variety of clinical settings. ${ }^{3}$

Since its inception, DFT has evolved into a well-structured training programme and is currently managed by the Committee of Postgraduate Dental Deans and Directors (COPDEND). COPDEND published "A Curriculum for UK Dental Foundation Programme Training" in 2006 and it was updated most recently in 2015.4,5 Satisfactory completion of DFT requires FDs to record evidence of progressive attainment across all the competencies set out in the COPDEND curriculum in their on-line e-portfolio. ${ }^{6}$ The e-portfolio is a digital platform to allow FDs to record their progress and development. Foundation Training involves the use of workplace based assessments (WBAs). The two main WBAs are "A dental evaluation of performance tool (ADEPTs), which is a combination of a direct observation of procedure (DOP) with a mini clinical 
evaluation exercise (mini-CEX); and "Case based discussion" (CBD), which involves questioning and feedback from the ES following a presentation by the FD. Other WBAs include "multisource feedback" (MSF) and a "patient survey questionnaire" (PSQ). ${ }^{5}$ The assessment process involves an interim review of competence progression (IRCP) after 6 months and a final review of competence progression (FRCP) after 9 months.

Health Education England, London designed a two-site pilot for DFT to explore the benefits and challenges of FDs working within two training practices throughout the training year. The pilot involved the March 2016 cohort of 12 FDs and 12 approved DFT practices in London. The aims of the pilot were to enhance the learning experience of FDs by providing them with an opportunity to train with two supervisory teams and develop a broad clinical experience in two practice environments with a different case-mix.

The practices and trainees were 'paired' to undertake the two-site pilot with each trainee working two days a week in both practices. FD 'A' worked in Practice 1 on Mondays and Tuesdays and in Practice 2 on Wednesdays and Thursdays alternating with Trainee B. Fridays were reserved as study days. The two training practices and two trainees worked as a quartet in organising the teaching and fulfilment of the FT curriculum. Each trainee had tutorials and WBAs in alternate practices on alternate weeks so each had experience of teaching at both practices. Each trainee had one contract of employment with Practice A and this contract allowed them to work parttime (Wednesdays and Thursdays) in Practice B.

Each FD had an educational agreement with HEE for both practices. The trainers were required to be in the practice 4 days per week, to provide two days of clinical 
supervision for each FD. Some ESs were not available for four days each week and were therefore supported by an "Assistant Educational Supervisor" (AES) who was approved by HEE to be responsible for clinical supervision of the FD in the absence of the ES. This allowed the FDs to work under supervision throughout the week. This arrangement was an advantage over the standard format of DFT where most ESs are only mandated to supervise FDs for three days per week.

The aim of this paper is to present early evaluation of the two-site pilot regarding its feasibility, management and impact on the learning experiences of FDs through direct engagement with the stakeholders. 


\section{METHODS}

A mixed methods approach based on semi-structured interviews, focus groups and questionnaires was used for evaluation of the two-site pilot as depicted in Figure 1. Following enrolment on the pilot, one-to-one qualitative semi-structured interviews were conducted with the FDs and ESs. The aim of the interviews was to gauge the expectations and concerns regarding the pilot. After 3 months of training, separate focus groups were conducted with the FDs and ESs to explore their initial experiences and challenges of training at two sites.

A purposely designed questionnaire was administered online to FDs and ESs after completion of six months of training. The questionnaire consisted of 16 items, grouped into three subscales; Relationship with trainee / educational supervisors (5 items), Learning Experience (5 items), and Practice Environment (5 items). All items were responded to using five-point Likert agreement scales. The questionnaire also included three open-ended items. Prior to administration, the questionnaire was piloted with six participants (three FDs and three GDPs).

Following completion of the training, FDs completed a questionnaire on paper. All items were responded to using five-point Likert agreement scales as described previously. Prior to administration, the questionnaire was piloted with three FDs. The aim of the questionnaire was to gauge their perceptions regarding their overall learning experience.

In preparation to run the two-site pilot, a comprehensive analysis of its strengths, weaknesses, opportunities and threats (SWOT) was undertaken by HEE. A range of

stakeholders were also consulted including National Health Service (NHS), UK Committee of Postgraduate Dental Deans and Directors (COPDEND), British Dental 
Association (BDA), Chief Dental Officer (CDO), ESs, and previous FDs. The evaluation was carried out as part of quality assurance and complies with standard ethical guidelines. The participants were informed about the purpose and scope of the evaluation. The participation of FDs and ESs was voluntary and they were consented appropriately. Pseudonyms were used to protect participants' identity and the data were analysed anonymously. All interviews and focus groups were recorded using a digital audio device and transcribed verbatim. All phases of the evaluation were conducted by an experienced external academic who was appointed by Health Education England to provide an independent review of the first year of the pilot.

\section{Data Analysis}

The qualitative data were analysed thematically using N Vivo 11 (QSR International Pty Ltd, Doncaster, Vic., Australia). Preliminary coding of the data sets was carried out by systematic reading of the transcripts. The nodes were collapsed into broader codes using an iterative process. Links between nodes were then established to develop tree nodes which facilitated mapping of the connections within the data. Thematic analysis was used to identify broad areas, which captured the views and experiences of the participants.

The data from questionnaires were analysed using SPSS 22 (IBM Corp. Released 2013. IBM SPSS Statistics for Windows, Armonk, NY: IBM Corp).

The aggregated results were shared with all participants during a debriefing session towards the end of the training year. The participants across the board expressed their unanimous agreement with the results and interpretations. 


\section{RESULTS}

Foundation dentists $(\mathrm{N}=12)$, ESs $(\mathrm{N}=15)$ and $\mathrm{AESs}(\mathrm{N}=7)$ participated in the two-site pilot.

\section{Semi-structured qualitative interviews}

All FDs were very positive and enthusiastic regarding their training. Having met their ESs in both practices, all FDs seemed to be comfortable. Most FDs expected that working in two practices under trainers with different interests and approaches would equip them with a broader skill set.

"I really want to do more endos and surgicals because I didn't do many at the Uni, so one of my trainers does a lot of endos and the other do lots of paeds and extractions and that's what I exactly wanted". Foundation Dentist 5

The ESs, on the other hand, expressed cautious optimism and shared several concerns. Opportunities to gain experience in two practices and managing patients with different treatment needs appeared to be the main advantage of the two-site pilot.

"They will be working in two different practices with two different teams, the environment will be different, this will enhance their adaptive skills and give them a broad-based experience. In future, they may be working part-time in different practices and that may be crucial". Educational Supervisor 1

The ESs across the board considered the administrative workload involved in training two FDs to be quite challenging for themselves as well as their practice staff. 
"I think it will be will difficult to run administratively, it is very difficult for the staff to get used to working with two different trainees; you need a dedicated team of administrators to make it work". Educational Supervisor 2

The key concerns expressed by the ESs were that the FDs would take longer to settle down in two practices simultaneously building a rapport with the practice staff was likely to be more challenging; risk of comparison between the two teams of supervisors; and the split-week working pattern of FDs was likely to cause breaks in the continuity of patient-care.

"If they are going to be working part time in each practice, they will take longer to settle down and the treatments are also going to take longer to complete".

Educational Supervisor 5

\section{Focus groups}

Separate focus groups were organised for ESs and FDs after completion of the first three months. The main themes emerging from the data analysis of focus groups are discussed below.

\section{Triangulation of Feedback}

The opportunity to obtain feedback from multiple ESs based in two independent practices was perceived to be one of the main benefits of the two-site pilot and these views were shared by participants across the board.

"Having another trainer is a positive aspect and the trainees can benefit from triangulation of the feedback they receive from different trainers". Educational Supervisor 9 
"It is good to get feedback on my performance from two experienced trainers with slightly different backgrounds and approach to treatment planning, it gives me an opportunity to reflect more”. Foundation Dentist 2

\section{Variety of Patients}

Participants across the board felt that working in two practices provided a better case mix for FDs due to differences in the treatment needs of patients and the interests of the practices. This was perceived to be a significant advantage by the FDs as it seemed to provide them with a greater breadth of clinical experience.

"I see a lot more prosthetics and restorative in one practice and more oral surgery and perio in the other practice, so it is good". Foundation Dentist 8

\section{Continuity of Training}

The ES expressed concerns regarding a lack of continuity of contact with the FDs which was not conducive to effective supervision. The ESs found it difficult to establish a relationship with the FDs at a professional as well as personal level.

"My trainee number A worked on Mondays and Tuesdays and there were three bank holidays and she was off-sick one day... and it took us longer to get used to each other". Educational Supervisor 4

The main concern was that the limited availability of FDs meant that it took longer to identify areas of weaknesses and there a risk of weaker trainees slipping through the net. 
"It is much easier for the weaker trainee to stay away from the radar and there is a risk they much slip through my fingers --- It took me two months to realise that she could not do the basics, like holding a hand-piece and taking radiographs".

Educational Supervisor 7

The ES also felt that providing feedback to FDs was proving to be more challenging due to potential confusion between the two FDs and it was hard to keep track of previous discussions.

Breaks in continuity of training were also mentioned by the FDs. However, they felt this could be improved through better planning and greater communication between the ESs.

"There is a lot of stress involved in completing the feedback from two trainers when one disagrees with the other, and there is a lot of chasing up to do, I think the trainers from two practices need to talk to each other more for planning the tutorials and discussing the feedback". Foundation Dentist 9

\section{Continuity of Patient Care}

Both ESs and FDs identified lack of continuity of patient care as a key challenge with the pilot. Several factors contributed to lack of continuity of patient care were mentioned. The split week afforded less time for FDs to plan and complete treatments for their patients. Moreover, if patients returned in an emergency due to postoperative pain, they had to be seen by a different clinician on certain occasions. The split week also meant that one trainee was unable to attend practice meetings. 
Overall, the ESs were more concerned with the lack of continuity of patientcare in comparison to FDs and this theme dominated the focus group for the ESs.

"If they were there for 4 days each week, it is easier for them to plan and go through their lists, now they are there in my practice only for 2 days. When they come on a Monday morning, it's head on- they haven't had a chance to look ahead, plan or discuss their cases .... So, there is lack of preparedness to plan treatment sessions". Educational Supervisor 11.

Some FDs $(\mathrm{N}=5)$ also recognised lack of continuity of patient-care and they focused on delays in treatment completions and being unavailable to deal if their patients attend in emergency.

"Some patients can only come on certain days of the week and sometimes it means temporising an endo for 3-4 weeks, if I was there all week this may only be 1 to 2 weeks - Sometimes it is the lab work, patients may have to wait for 2 weeks for a denture try-in". Foundation Dentist 4

Administrative Workload and Logistics

The ES felt that having two FDs entailed doing twice the work rather than half as a separate induction had to be organised for each FD and often ESs needed to go over some basic issues with each FD separately.

"I find the work is twice rather than half for each trainee, I have to go over everything twice and this is double the work I did previously". Educational Supervisor 3 
"Our receptionist teams have got double the work as well, our nurses are finding double the work because the repetition that comes in is taking them twice as long to get the FDs comfortable". Educational Supervisor 1.

Completion of the e-portfolio was also raised as a major source of increased workload both by the ESs as well as FDs.

"We have to double the work, double the DOBs, MSF, ESR and E portfolio. I spend my life worrying about the portfolio more than actually doing dentistry". Foundation Dentist 3.

Traveling between two practices allocated to each FD was perceived to be a potential challenge during the planning of the two-site pilot. However, all FDs reported they did not experience any difficulties. 


\section{Online Questionnaire (6 Months)}

Separate questionnaires were designed for FDs and ESs. The results of the online questionnaires from FDs and ESs were combined and depicted in Table. 1

A comparison of the reliability of average ratings for each question between FDs and ESs showed an Intra-class Correlation Coefficient (ICC) of $0.14(F(11,4.23)=1.69$, $\mathrm{p}=0.317,95 \% \mathrm{Cl}=-0.22-0.58)$. These comparisons suggest that the extent to which FDs agree on their responses to each other is very low, but that the extent to which ESs agree on their responses to each item is much higher. Thus, ratings of FDs were more variable in their views, whereas the ratings by ESs were much more similar with respect to each other. The participants also highlighted the positive aspects, drawbacks and challenges of the two-site pilot in open-ended responses as shown in Table 2.

The participants also provided several recommendations for further improvements. The FDs expected HEE London to provide the timetable for term dates and study days for the entire year in advance to help FDs plan their annual leave. FDs also suggested better communication and further engagement between paired practices to plan the tutorials. In addition, they reiterated the need for modification of the e-portfolio to reduce the paper clutter. The ESs recommended joint inductions for the FDs at each practice and better adaptation of the e-portfolio to the two-site pilot to reduce the workload. They also stressed the need for more prompt payments by the BSA. 


\section{Questionnaire (End of training)}

All FDs ( $\mathrm{N}=12)$ completed the post-training questionnaire on paper and the results are shown in Table 3. All participants provided high scores for their learning experience and reported improvements in their applied clinical knowledge, clinical skills, communication, team working and professionalism. The two-site model was recommended for future FDs by $75 \%$ of the participants $(\mathrm{N}=9)$ but $25 \%(\mathrm{~N}=3)$ were unsure. 


\section{DISCUSSION}

DFT is a period of transition from undergraduate dental student to an independent dental practitioner. However, many studies on FDs have shown gaps in clinical training and lack of confidence in training practices. ${ }^{7-10}$ The two-site pilot represents a major modification in the format of the DFT in England. Following SWOT analysis and feedback from the stakeholders, it was considered appropriate to run the pilot on a small scale with the March cohort of FDs. It was aimed at improving the learning experience of FDs by allowing them to work in two practices under two independent teams of ESs. Personal relationship between trainees and their supervisors is likely to have an impact on the feedback provided during WBAs. ${ }^{11}$ Therefore, the two-site pilot may serve to enhance the external validity of WBAs by triangulation of feedback of performance by two independent teams of ESs.

Positive perceptions were expressed by FDs with regards to working with two independent teams of supervisors and found it to be helpful in boosting their learning experience. Feedback from the ESs was also reported as an important factor in enhancing their skills during clinical sessions on patients. The ESs also unanimously endorsed the benefits of triangulation of feedback. These findings underscore the importance of effective feedback as reported previously. ${ }^{12-15}$ FDs also recognised that feedback should not be solely regarded as the responsibility of the ESs and FDs should proactively seek feedback to improve their performance and integration in the practice.

Dissatisfaction with ESs during FT in dentistry has been reported previously. 7, 8, 16 Although $25 \%$ of FDs $(\mathrm{N}=3)$ in the two-site pilot expressed dissatisfaction with the 
quality of supervision in one of the practice, they received adequate supervision in the other practice. Therefore, working in two practices, allowed some degree of compensation for any perceived gaps in supervision. However, direct comparison between practices and ESs will be inevitable with the two-site model. Many would argue that this is an important strength of this model of training. However, all should be mindful of a FD developing a 'favourite' ES and practice at the disadvantage of the other.

Participants across the board recognised that working in two practices with varying patient demographics provided a good case mix for the FDs and improved the breadth of their clinical experience. FDs are expected to gain experience in treating patients with diverse treatment needs. ${ }^{5}$ Studies on medical trainees also emphasise the importance of case mix and show a positive correlation between case mix and confidence of trainees. ${ }^{17-20}$ The two-site pilot appears to be helpful in improving the case mix for the reported cohort of FDs. Given the challenges of organisation and funding, the demographics of the practice pairs must be assessed to ensure that patients' treatment needs in each practice are different so that the FDs gain experience with a good case mix overall.

One of the major challenges of the two-site pilot, as perceived by the participants, was the increased workload. The ESs reported the organisation of separate inductions, tutorials, and completion of the e-portfolios to be time-consuming. The impact of workload associated with completion of e portfolio and MSF is well-recognised and reported in studies on medical trainees. ${ }^{21}$ Another key concern expressed by the participants was the lack of continuity of patient care and delays in treatment. Although delays in treatment completions may be unavoidable to a certain extent, it is 
recommended that FDs play a more active role in managing their clinical appointment books as well as communicating with the laboratory staff. Furthermore, it would be helpful to keep a log of delays in treatment and an audit in the future would be useful to measure the impact on continuity of patient care more objectively.

Several limitations of the two-site pilot need to be recognised. Firstly, it was conducted on a small scale and involved a single cohort / scheme of FDs in London. Ideally inclusion of a control group consisting of trainees from a conventional DF scheme would have been helpful for a more meaningful comparison. Given this pilot represents a major shift in the training model which required considerable administrative work and logistics, it was not possible to FDs from conventional schemes. HEE has therefore, decided to continue the two-site training model for another year with the 2017/18 cohort of 12 FDs enrolled on the March 2017 scheme. It is felt that that extended evaluation of the training model will provide additional data about its strengths and weaknesses. In addition, it is hoped that the 'lessons learned', particularly regarding sharing roles with practice organisation and ES training function, can be in place for the second evaluation. Finally, the ESs were not offered to complete an end of training questionnaire due to time constraints. Although it would have been helpful to gauge if the views of ESs might have changed over time, they were given opportunities to provide additional feedback during the debriefing sessions at the end of training. The ESs showed unanimous agreement with the results and interpretations.

Based on 12-month feedback from the 2016/17 cohort, several steps have been taken to reduce the workload for the ESs and FDs. The new cohort of FDs will have joint induction at their practices. Moreover, MSF from both practices will be recorded online 
without the need for any paper trails. The key dates have been provided to the ESs and FDs in advance and the need for better communication amongst ESs in each of the paired practice to plan tutorials has been reiterated. It is envisaged that these steps will facilitate the management of the two-site training of FDs and address many of the concerns raised by the stakeholders. 


\section{CONCLUSIONS}

This paper reports the evaluation of an innovative pilot for dental foundation training in England. It highlights the advantages, challenges and opportunities of training of FDs at two dental practices. A majority (75\%) of the FDs as the end-users of the training supported continuation of the model. The findings of this study will hopefully generate debate amongst stakeholders regarding the future structure of DFT to achieve a higher quality training experience involving triangulation of data which should result in improved care for patients and improved confidence in young dentists. 
Acknowledgements:

The authors are grateful to all foundation dentists, educational supervisors who participated in this pilot. We are also thankful to staff members of dental practices and Health Education England who contributed immensely in running this scheme.

\section{Disclosure}

None of the authors have any conflict of interest. 


\section{REFERENCES}

1. The National Health Service (Performers Lists) Regulations 2005. Statutory Instrument 2005 No. 3491. London: The Stationery Office, 2005.

2. Patel R, Batchelor PA. Experiences of vocational trainees on their preparation and application for vocational training. Br Dent J. 2007 Mar 24;202(6):345-9.

3. Foundation Programme Curriculum. Available at http://www.foundationprogramme.nhs.uk/pages/curriculumeportfolio/curriculum-assessment (accessed January 2017).

4. Committee of Postgraduate Dental Deans and Directors. A curriculum for UK Dental Foundation Programme training. London. Department of Health, 2006. Available from http://www.copdend.org.uk (accessed January 2017).

5. Committee of Postgraduate Dental Deans and Directors. Dental foundation training professional development portfolio. London: COPDEND, 2009. Available at http://www.copdend.org.uk (accessed January 2017).

6. UK Committee of Postgraduate Deans and Directors. Dental foundation training policy statement. 2011. Available at http://www.copdend.org/content.aspx?Group=foundation\&Page=foundation_policystatement (accessed January 2017).

7. Palmer NO, Kirton JA, Speechley D. An investigation of the clinical experiences of dentists within the national dental foundation training programme in the North West of England. Br Dent J. 2016 Sep 23;221(6):323-8.

8. Coe J. Mind the gap: Are dental trainees satisfied with their clinical experience? Br Dent J. 2016 Oct 7;221(7):406. 
9. Gilmour A, Jones R, Bullock A. Dental Foundation Trainers' Expectations of a Dental Graduate. COPDEND and Cardiff University. 2012.

10.Wieder M, Faigenblum M, Eder A, Louca C. An investigation of complete denture teaching in the UK: part 2. The DF1 experience. Br Dent J. 2013 Sep;215(5):229-36 .

11. Bok HG, Jaarsma DA, Spruijt A, Van Beukelen P, Van Der Vleuten CP, Teunissen PW. Feedback-giving behaviour in performance evaluations during clinical clerkships. Med Teach. 2016;38(1):88-95.

12. Manogue M, Brown G, Foster H. Clinical assessment of dental students: values and practices of teachers in restorative dentistry. Med Educ. 2001

13. Archer J C. State of the science in health professional education: effective feedback. Med Educ 2010; 44: 101-108.

14. Carr S. The Foundation Programme assessment tools: an opportunity to enhance feedback to trainees? Postgrad Med J. 2006 Sep;82(971):576-9.

15. Jackson D, Wall D. An evaluation of the use of the mini-CEX in the foundation programme. Br J Hosp Med (Lond). 2010 Oct;71(10):584-8.

16. Ralph JP, Mercer PE, Bailey H. A comparison of the experiences of newly qualified dentists and vocational dental practitioners during their first year of general dental practice. Br Dent J. 2000 Jul 22;189(2):101-6.

17. McNair R, Griffiths L, Reid K, Sloan H. Medical students developing confidence and patient centredness in diverse clinical settings: a longitudinal survey study. BMC Med Educ. 2016 Jul 15; 16:176.

18. Van der zwet J, Hanssen V G A, Zwietering P J, Muijtjens A M M, Van der vleuten C P M, Metsemakers J F M et al. Workplace learning in general 
practice: Supervision, patient mix and independence emerge from the black box once again. Med Teach 2010; 32: 294-299.

19. Wimmers P F, Schmidt H G, Splinter T A. Influence of clerkship experiences on clinical competence. Med Educ 2006; 40: 450-458.

20. de Jong J, Visser M, Van Dijk N, Vleuten C V D, Wieringa-de Waard M. A systematic review of the relationship between patient mix and learning in workbased clinical settings. A BEME systematic review. Med Teach 2013; 35: e1181-e1196.

21. Hrisos S, Illing JC, Burford BC. Portfolio learning for foundation doctors: early feedback on its use in the clinical workplace. Med Educ. 2008 Feb;42(2):21423. 
Qualitative Interviews (Pre-training)

Foundation Dentists \& Educational Supervisors<smiles>[CH]</smiles>

\section{Focus Groups (3 Months)}

Foundation Dentists \& Educational Supervisors<smiles>[CH]=C</smiles>

\section{Questionnaire (6 Months)}

Foundation Dentists \& Educational Supervisors<smiles>[SiH3]</smiles>

Questionnaire (Post-training)

Foundation Dentists

Figure 1 Summary of methods used in the evaluation 


\begin{tabular}{|c|c|c|c|c|c|c|c|}
\hline \multirow[t]{2}{*}{$\mathbf{Q}$} & \multirow[t]{2}{*}{ Text } & \multicolumn{3}{|c|}{$\begin{array}{l}\text { Foundation } \\
\text { Dentists }\end{array}$} & \multicolumn{3}{|c|}{$\begin{array}{l}\text { Educational } \\
\text { Supervisors }\end{array}$} \\
\hline & & $\mathrm{N}$ & Mean & SD & $\mathrm{N}$ & Mean & SD \\
\hline & $\begin{array}{l}\text { Relationship of Trainees with } \\
\text { Educational Supervisors }\end{array}$ & & & & & & \\
\hline 1 & $\begin{array}{l}\text { Supervisors attach appropriate } \\
\text { importance to the learning needs } \\
\text { of trainees }\end{array}$ & 12 & 4.42 & 0.51 & 13 & 4.92 & 0.28 \\
\hline 2 & $\begin{array}{l}\text { Supervisors devote adequate } \\
\text { time to address the learning } \\
\text { needs of trainees }\end{array}$ & 12 & 4.00 & 1.21 & 13 & 4.85 & 0.38 \\
\hline 3 & $\begin{array}{l}\text { Trainees receive adequate } \\
\text { feedback from supervisor to } \\
\text { support their learning }\end{array}$ & 12 & 4.25 & 0.62 & 13 & 4.92 & 0.28 \\
\hline 4 & $\begin{array}{l}\text { Trainees get adequate } \\
\text { opportunities to ask questions } \\
\text { from the supervisor when } \\
\text { providing clinical treatment }\end{array}$ & 12 & 3.50 & 1.88 & 13 & 4.92 & 0.28 \\
\hline & Learning Experience & & & & & & \\
\hline 5 & $\begin{array}{l}\text { The training has been good for } \\
\text { the learning of the trainees }\end{array}$ & 12 & 4.33 & 1.37 & 13 & 4.69 & 0.48 \\
\hline 6 & $\begin{array}{l}\text { The training has helped trainees } \\
\text { improve their clinical skills }\end{array}$ & 12 & 4.17 & 1.59 & 13 & 4.77 & 0.44 \\
\hline 7 & $\begin{array}{l}\text { The training has enhanced } \\
\text { trainees' motivation to practice } \\
\text { dentistry }\end{array}$ & 12 & 3.58 & 0.90 & 13 & 4.62 & 0.77 \\
\hline 8 & $\begin{array}{l}\text { The Deanery provided adequate } \\
\text { support for the pilot }\end{array}$ & 12 & 3.83 & 0.39 & 13 & 4.08 & 0.64 \\
\hline & Practice Environment & & & & & & \\
\hline 9 & $\begin{array}{l}\text { Patient-care at this practice is } \\
\text { individualised for each patient }\end{array}$ & 12 & 4.00 & 1.04 & 13 & 4.38 & 1.12 \\
\hline 10 & $\begin{array}{l}\text { Patients' best interests are } \\
\text { prioritised at this practice }\end{array}$ & 12 & 4.25 & 1.14 & 12 & 4.92 & 0.29 \\
\hline 11 & $\begin{array}{l}\text { There is a good team-working } \\
\text { ethos at this practice }\end{array}$ & 12 & 3.83 & 1.40 & 13 & 4.38 & 1.12 \\
\hline 12 & $\begin{array}{l}\text { Each trainee is treated as an } \\
\text { individual rather than as 'another } \\
\text { trainee'. }\end{array}$ & 12 & 4.08 & 1.24 & 13 & 5.00 & 0.00 \\
\hline
\end{tabular}

\section{Table 1 Responses to Questionnaire After 6 Months of Training}

*Response categories: Strongly disagree $=1$; Disagree=2; Unsure=3; Agree=4;

Strongly Agree $=5$ 


\section{Positive Aspects}

Feedback from multiple trainers

Experience of working in different socioeconomic areas and exposure to patient with a variety of treatment needs / expectations Breaks up the week nicely and keeps both practices interesting and busy.

When on practice is quiet e.g., summer holidays, the other is busy thus experience can still be gained or in some cases made up Great to see how dental professionals work differently yet keeping patients first.

Exposure to different managerial styles
Triangulation of feedback from multiple trainers

Wider experience working in different environments and getting used to working with different teams

Exposure to different practice environments

Triangulation of appraisal between trainers

FDs gain experience in two practices and have multiple trainers with several opinions on how to address the same problem

\section{Drawbacks and Challenges}

Longer time taken to feel settled, adjust to $\quad$ Longer induction period; double the work.

different materials and labs

Double the amount of work on e-portfolio

The e-portfolio is not geared up for 2 FDs. Having to print and upload paper records for FD (B) is time consuming.

Unable to control my diary when away from the other practice

Takes longer to complete treatments

Patient continuity is compromised Treatments take too long and more increased work for the trainers and practice staff Patients have limited availability of their dentist and may need to wait for several weeks for an appointment Continuity of care is compromised Takes longer to feel part of the team, Less time spent with each FD. Risk of losing continuity with the trainer is disrupted

Organising tutorials and WBAs is more track of discussions and cases. Lack of mentoring opportunities complicated

Back biting and comparisons

Table 2 Responses to Open-ended Questions 


\begin{tabular}{llllllll}
\hline Q & Text & N & Mean $^{*}$ & SD & Min & Max & Range \\
\hline Q1 & $\begin{array}{l}\text { Working in two practices has been a } \\
\text { good experience }\end{array}$ & 12 & 4.50 & 0.52 & 4 & 5 & 1 \\
Q2 & $\begin{array}{l}\text { My training helped me to enhance } \\
\text { my applied dental knowledge }\end{array}$ & 12 & 4.25 & 0.97 & 2 & 5 & 3 \\
Q3 $\begin{array}{l}\text { My training helped me to enhance } \\
\text { my clinical skills }\end{array}$ & 12 & 4.75 & 0.45 & 4 & 5 & 1 \\
Q4 $\begin{array}{l}\text { My training helped me to enhance } \\
\text { my communication skills }\end{array}$ & 12 & 4.58 & 0.67 & 3 & 5 & 2 \\
Q5 $\begin{array}{l}\text { My training helped me to enhance } \\
\text { my team working skills }\end{array}$ & 12 & 4.42 & 1.16 & 1 & 5 & 4 \\
Q6 $\begin{array}{l}\text { My training helped me to enhance } \\
\text { my professionalism }\end{array}$ & 12 & 4.42 & 0.67 & 3 & 5 & 2 \\
Q7 $\begin{array}{l}\text { Overall I am satisfied with my } \\
\text { training }\end{array}$ & 12 & 4.33 & 0.89 & 2 & 5 & 3 \\
Q would recommend the two-site & 12 & 3.83 & 0.94 & 2 & 5 & 3 \\
model for future trainees & & 12 & &
\end{tabular}

Table 3: Responses to End-of-Training Questionnaire by Foundation Dentists

*Response categories: Strongly disagree=1; Disagree=2; Unsure=3; Agree=4;

Strongly Agree $=5$ 


\section{Appendix: Dental Undergraduates Preparedness Assessment Scale}

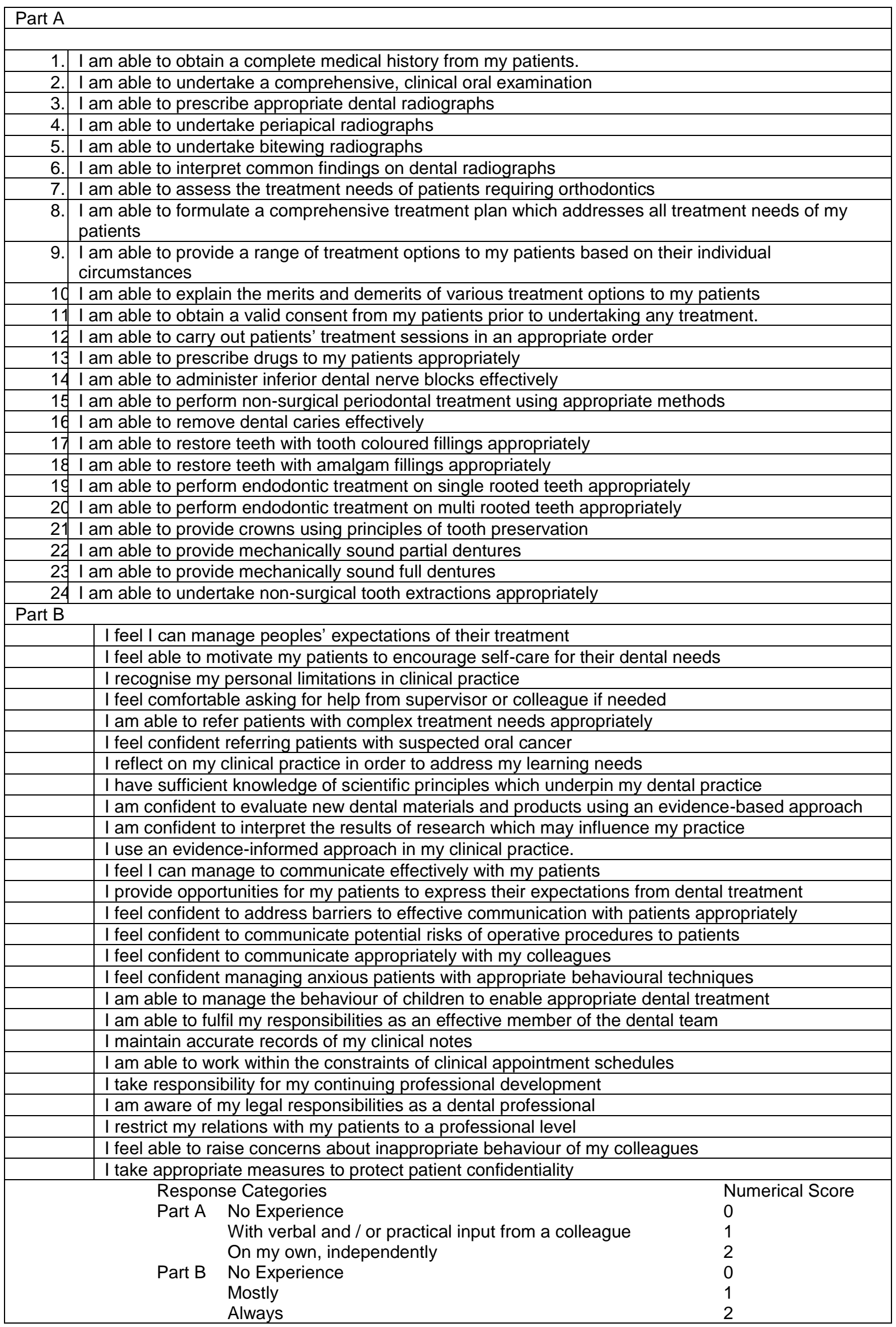


